Article

\title{
Improving Medical Student's Knowledge and Understanding of Fecal Incontinence
}

\author{
ChunHei Li ${ }^{1}$, Jody Parker ${ }^{2, *}$, Nicola Reeves ${ }^{2}$ (D) and Julie Cornish ${ }^{2}$ \\ 1 School of Medicine, Cardiff University, Cardiff CF10 3AT, UK; chun.li19@imperial.ac.uk \\ 2 Department of Colorectal Surgery, University Hospital of Wales, Heath Park, Cardiff CF14 4XW, UK; \\ Nicola.reeves@wales.nhs.uk (N.R.); Julie.Cornish@wales.nhs.uk (J.C.) \\ * Correspondence: parkerjl@cardiff.ac.uk
}

Received: 1 July 2020; Accepted: 10 August 2020; Published: 11 August 2020

check for updates

\begin{abstract}
Introduction. Knowledge of fecal incontinence (FI) in medical professionals is poor. Undergraduate education is limited despite its relevance to many specialties. Our aim was to review undergraduate curriculum requirements for FI across the UK and evaluate the impact of a teaching tool on medical student knowledge. Methods. Governing bodies and medical school curricula were identified and searched for FI knowledge requirements. A questionnaire was developed to assess undergraduate exposure to FI teaching. This information was consolidated with a discussion group involving medical students and used to develop an e-learning module. Intervention was performed by trialing the module in a group of medical students and evaluated with feedback. Results. There is a considerable absence of undergraduate learning requirements for FI. Only $19 \%$ of medical students had received teaching on the subject despite there being a demand for more coverage $(43 \%)$. A group discussion guided the development of an e-learning module. Introduction of this significantly improved medical students understanding in all aspects of diagnosis and management of FI. Conclusions. There is a shortfall in the undergraduate curriculum requirements for this common and debilitating problem. An e-learning module can enhance knowledge and understanding in medical students to improve patient care and management.
\end{abstract}

Keywords: education; medical student; surgery; fecal incontinence

\section{Introduction}

Fecal incontinence (FI) is the involuntary loss of control of feces and has a prevalence of $8.4 \%$ [1]. Living with FI has an immense psychosocial impact and plays a major role in an individual's quality of life (QOL) [2]. Patients with FI often feel conscious about their own body image and have low self-esteem which can result in social isolation [3,4]. In extreme cases, individuals can even become housebound $[3,4]$. The problem is more prevalent in the elderly or frail, parous women and patients with underlying neurological conditions or cognitive impairment. Up to $37 \%$ of primiparous women report symptoms of FI towards the end of their pregnancies with $10 \%$ noting the adverse impact of FI on their QOL [5]. The prevalence of FI is likely under reported due to the embarrassing nature of the problem $[1,3,6]$.

FI is associated with high economic costs [7]. Early treatment of the problem shows significant improvement in QOL [2], therefore, prompt recognition and intervention of FI are important. FI is a debilitating condition which all doctors should be aware of early on in their career as it is likely to present to a range of specialties and situations. Thekkinkattil et al. reported a limited awareness of investigations and treatment options in general practitioners for those with fecal incontinence [8]. Our center has anecdotally noticed an overall lack of awareness and knowledge in both medical 
students and junior doctors. Given the prevalence of FI and the cross over for multiple specialties, it seems logical to introduce the topic during medical school.

There were two aims of this study. The first was to establish undergraduate curriculum requirements and medical student exposure to teaching on FI in the UK. Secondly the impact of a newly developed educational tool based on the findings of the above on medical student knowledge was assessed.

\section{Methods}

An overview of the study design is shown in Figure 1. The period of data collection was between June and July 2019. The datasets used and/or analyzed during the current study are available from the corresponding author on reasonable request.

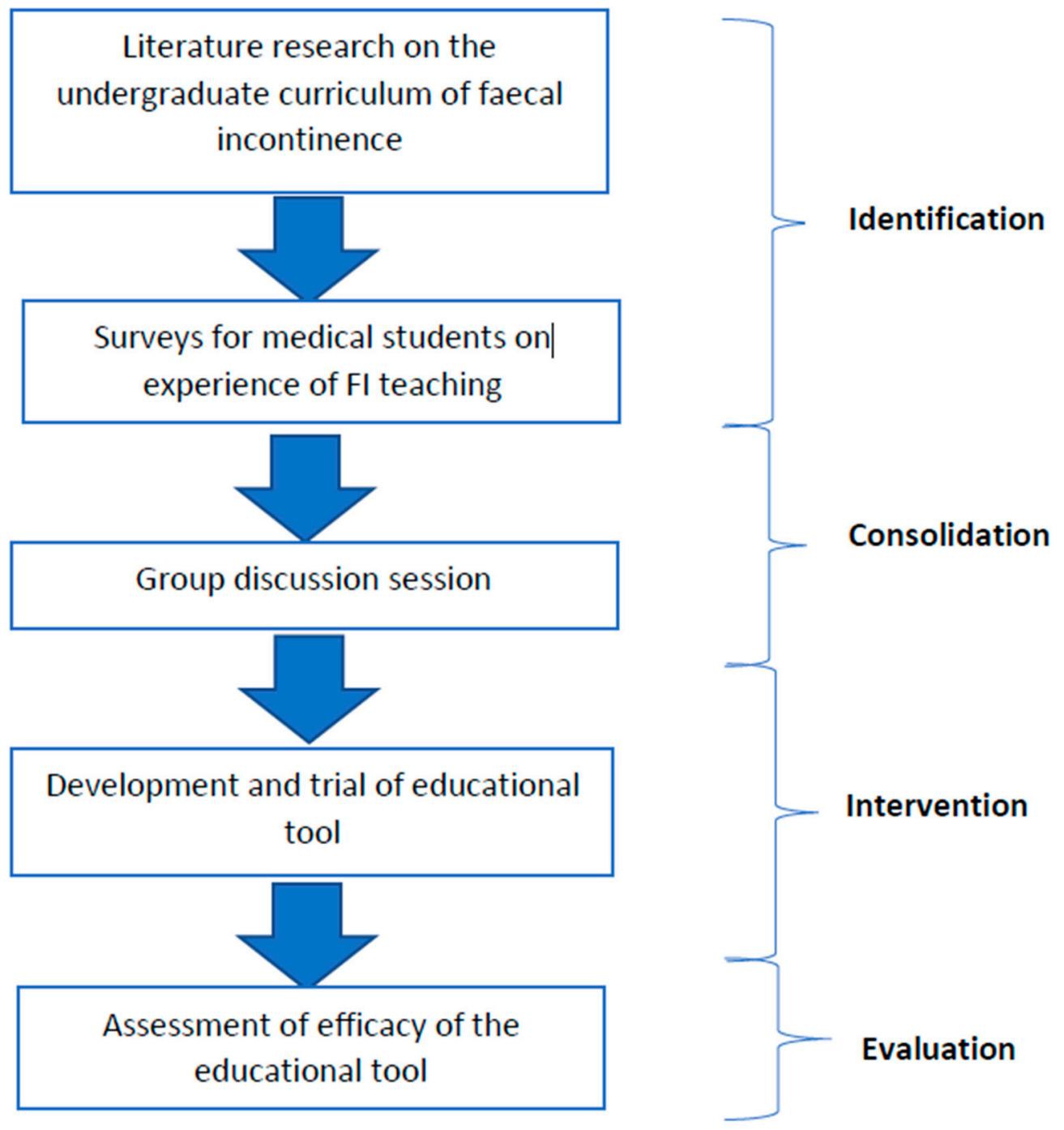

Figure 1. A flow chart demonstrating an overview of the study design.

Due to the invite only and voluntary nature of participation, ethical approval was deemed not necessary for this study.

\subsection{Assessment of the Undergraduate Curriculum}

A review of undergraduate learning outcomes on FI published by medical professional organizations was performed. All published undergraduate learning outcomes for relevant bodies were available online. The learning outcomes collected included the General Medical Council 
(GMC), Royal College of Surgeons (RCS), Royal College of Obstetricians and Gynaecologists (RCOG), Royal College of General Practitioners (RCGP), British Geriatric Society (BGS) and Royal College of Paediatrics and Child Heath (RCPCH). The documents were searched to identify any references to fecal or urinary incontinence.

There were 38 medical schools in the UK which were contacted via email to request their undergraduate medical curriculum to identify learning outcomes related to fecal incontinence. The submitted documents were again searched for any mention of fecal or urinary incontinence.

\subsection{Assessment of Medical Student Teaching Experience}

A questionnaire was designed to assess medical students' undergraduate experience of teaching on fecal and urinary incontinence. Questions included student exposure to teaching on this subject, the location and timing of teaching, their preferences for delivery of teaching and their planned specialty. The questionnaire was written in conjunction with a Consultant Colorectal Surgeon with expertise in FI and utilized guidance from the Association of Medical Education in Europe (AMEE) [9]. To optimize responses, the questionnaire was posted on an online forum subscribed to by all medical undergraduates at Cardiff University. It was also emailed to undergraduates through medical societies in addition to paper questionnaires being distributed at appropriate opportunities.

\subsection{Development of the Educational Tool}

A group discussion was set up involving medical students to gauge their understanding of FI. They were invited via the original questionnaire and contacted if willing to participate. The content was tape recorded and converted into a script for analysis using the $\mathrm{R}$ program. The educational tool format and content was formulated based on this discussion and the questionnaire responses from Section 2.2. It was created and content validated in conjunction with the same Consultant Colorectal Surgeon with expertise in FI.

\subsection{Trial and Assessment of Impact of Educational Tool}

Medical students who had not participated in the group discussion were invited to trial the educational tool. The students were asked to fill in a feedback forms before and after completing this. The feedback forms asked them to rate their confidence regarding the pathophysiology, identification and management of FI. Their responses before and after were compared with a paired sample $t$-test. A $p$-value less than 0.05 was considered statistically significant.

\section{Results}

\subsection{Assessment of the Undergraduate Curriculum}

The six national undergraduate curriculums outlined in Section 2.1 were assessed for learning requirements for fecal or urinary incontinence. Except for the Royal College of Obstetricians and Gynaecologists (RCOG), there was no mention of incontinence in any of these. The RCOG only covers urinary incontinence and there are no requirements concerning bowel incontinence.

A total of 38 medical schools were contacted for their undergraduate curriculum and there were 11 replies. A summary is shown in Table 1. Four medical schools declined to submit their curriculum for a variety of reasons. Of those who submitted their curriculums, the responses and documents were searched for any mention of incontinence. Of the seven responders, only one contained any learning requirements for FI. 
Table 1. Summary of responses from medical schools.

\begin{tabular}{ccc}
\hline Response & Number (Out of 38) \\
\hline No reply & 27 \\
Declined & & 4 \\
Curriculum submitted & Yes & 7 \\
\hline Urinary or bowel Incontinence included? & No & 6 \\
\hline
\end{tabular}

\subsection{Assessment of Medical Student Teaching Experience}

There were 100 medical student responses to the survey. The majority had teaching on bowel dysfunction $(75 \%)$ or urinary incontinence $(67 \%)$ during their training. The commonest modes of delivery were on placement $(28.8 \%)$, during lectures $(27.9 \%)$ or through case-based discussions $(20.2 \%)$ as shown in Figure 2. The commonest topics covered during teaching were diarrhea $(37.6 \%)$ and constipation (34\%). Despite there being a high incidence of teaching on bowel dysfunction, only $19.3 \%$ of respondents had teaching on FI and $6.6 \%$ had not received any teaching on these topics at all. Timing of teaching on bowel dysfunction is shown in Figure 3 and was commonest during the second and third years of medical school (33.3\% and $27.1 \%$ respectively) with very little in the final year $(3.3 \%)$.

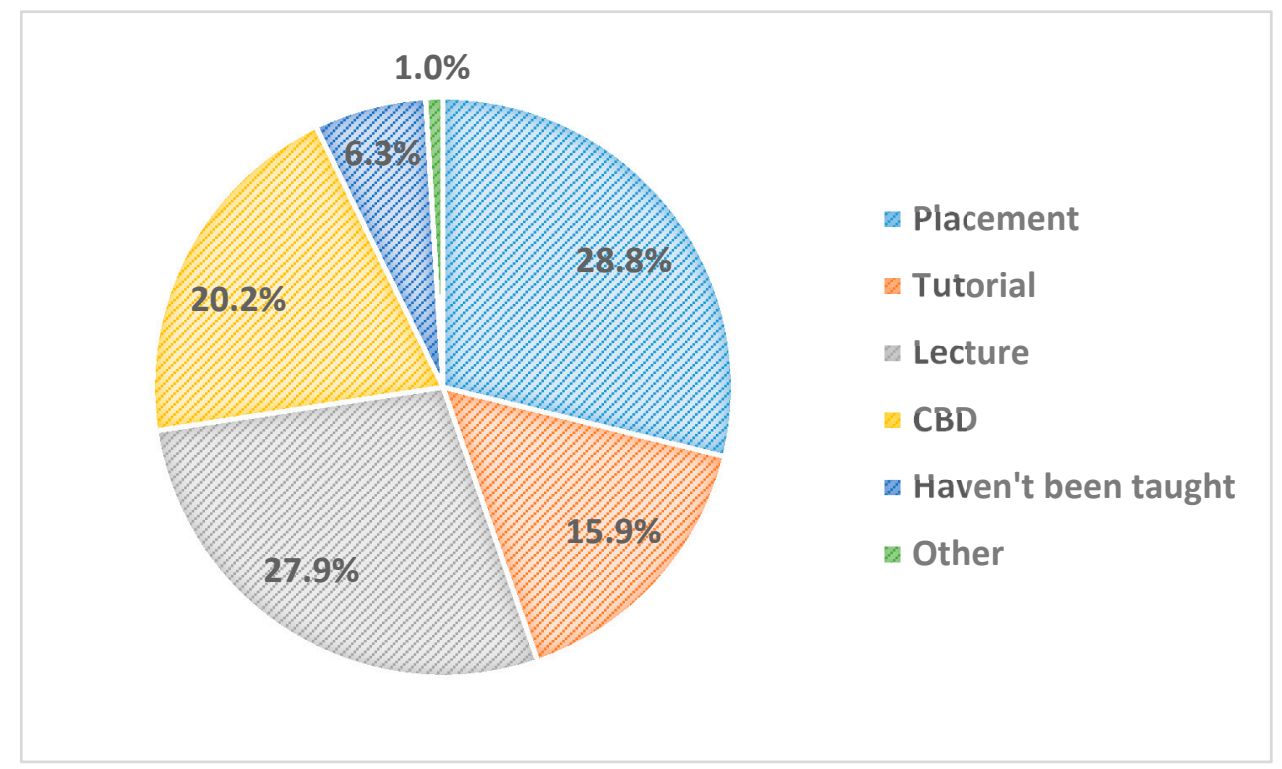

Figure 2. Modes of delivery for teaching on bowel dysfunction experienced by medical students.

Medical student encounters with bowel dysfunction patients were in a variety of clinical locations and are outlined in Figure 4. Only a minority had never encountered patients with bowel dysfunction $(5.7 \%)$. Of the group, $38 \%$ aimed to specialize in medicine in the future with $20 \%$ considering surgery. There were $12 \%$ considering general practice, $4 \%$ obstetrics and gynecology or $19 \%$ for other specialties. There was a considerable wish for further teaching on FI (43.3\%) compared to the other symptoms of bowel dysfunction including constipation $(26.4 \%)$ and diarrhea $(19.7 \%)$. Some students felt more teaching on FI was not required $(6.2 \%)$ but this was a considerable minority. There were a variety of opinions on the best method of delivery of teaching as shown in Figure 5. 


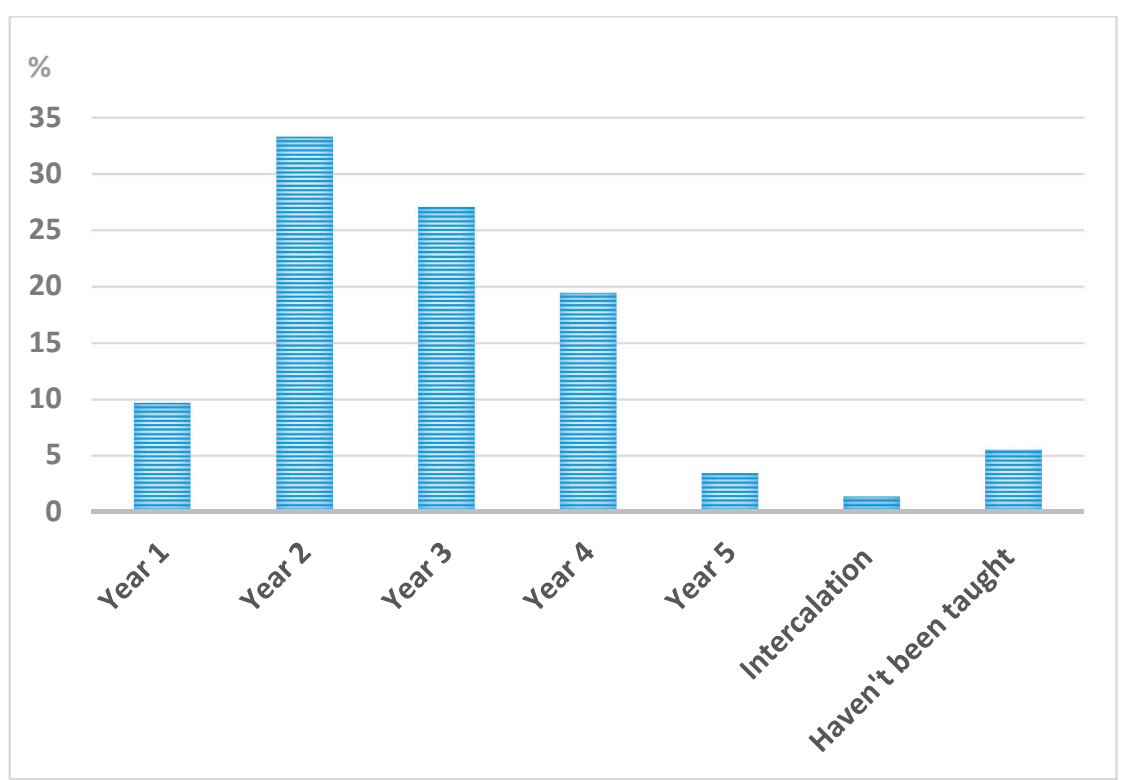

Figure 3. Year of study bowel dysfunction teaching was delivered.

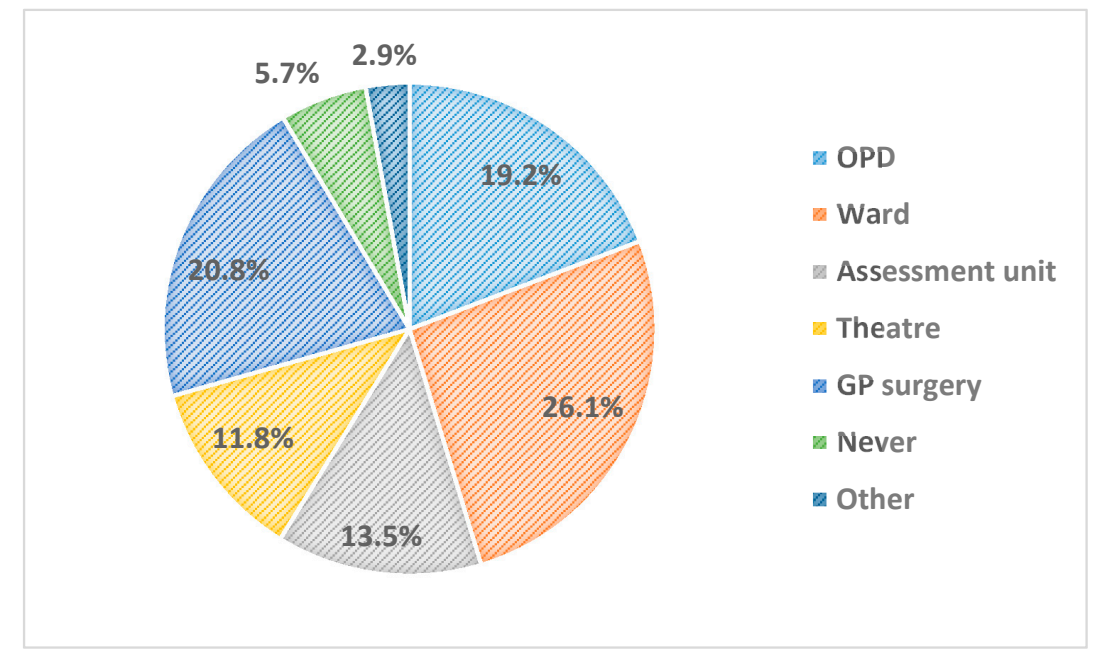

Figure 4. Locations medical students had encountered patients with bowel dysfunction.

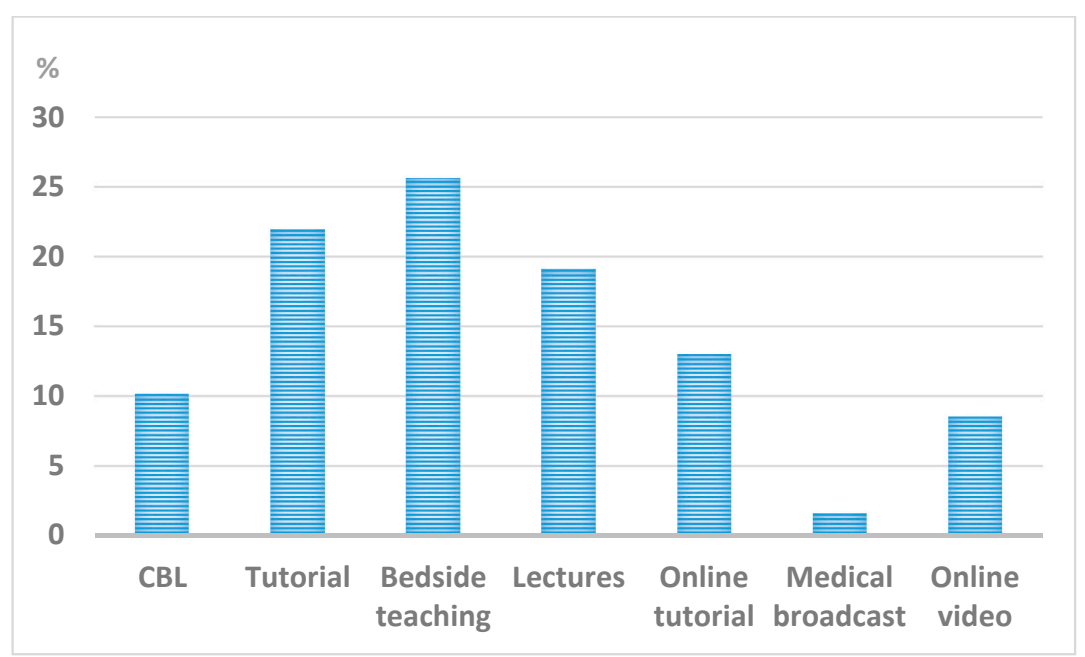

Figure 5. Preference of medical students for method of delivery of teaching for FI. 


\subsection{Development of the Educational Tool}

Nine students were selected to participate in the group discussion session. The appropriate knowledge requirements for FI and the most effective method of delivery were explored in an informal environment. The group discussion was recorded as an audio file and converted into text. This text was put through the R program to create a word cloud as shown in Figure 6. The recurrent themes from the discussion were identified as the areas of FI that should be included in the educational tool. There was general agreement that FI was not well taught during undergraduate training. Integration was thought of as important both in clinical placements and online learning tools.

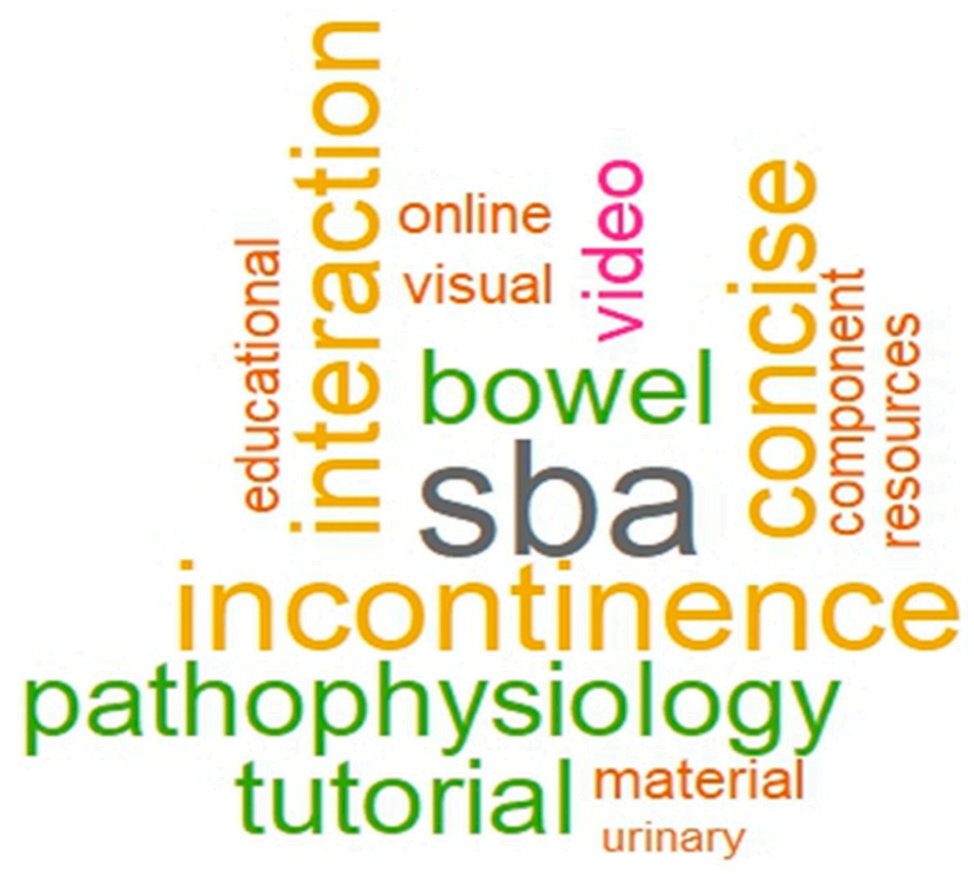

Figure 6. Word Cloud generated from the discussion group.

The discussion concluded that the most appropriate teaching method for FI was an online tutorial. As FI is an embarrassing condition for patients, this was a more pragmatic and sensitive choice than clinical teaching. An e-learning module was created using Xerte which is a free program. The contents and design of this module were based on the suggestions from the focused group and feedback from the questionnaires. This was validated by the previously mentioned Consultant Colorectal Surgeon to ensure quality and accuracy of the content. It can be viewed at https://xerte.cardiff.ac.uk/play_9972. There were 10 slides and it took approximately $45 \mathrm{~min}$ to complete. It covered physiology, anatomy, terminology, definitions, epidemiology, assessment and management of FI. The slides were illustrated and evidence based with references to appropriate guidelines, resources and charities. It incorporated patient stories and had details for further learning opportunities and contacts. The module ended with a multiple-choice test of twelve questions and a medical student feedback from.

\subsection{Trial and Assessment of Impact of Educational Tool}

At total of 20 medical students took the e-learning module with all completing the pre and post course feedback forms. These students were chosen at random and excluded those participating in the group discussion to avoid bias. After completing the module, the students had rated significant improvement in confidence on all aspects on the feedback form as shown in Table 2. 
Table 2. Confidence ratings scored out of ten $(0=$ no confidence, $10=$ completely confident $)$ before and after e learning module.

\begin{tabular}{cccc}
\hline Area Assessed & $\begin{array}{c}\text { Mean Confidence } \\
\text { Rating Before e-Module }\end{array}$ & $\begin{array}{c}\text { Mean Confidence } \\
\text { Rating After e-Module }\end{array}$ & $p$ Value (Paired Sample $\boldsymbol{t}$ Test) \\
\hline $\begin{array}{c}\text { Knowledge of anatomy and } \\
\text { pathophysiology of FI }\end{array}$ & 4.50 & 7.20 & $<0.001$ \\
\hline Identification of FI in patients & 4.56 & 6.75 & $<0.001$ \\
\hline Management of patients with FI & 3.56 & 6.75 & $<0.001$ \\
\hline $\begin{array}{c}\text { Understanding of the psychosocial } \\
\text { aspect of FI }\end{array}$ & 5.06 & 7.19 & $<0.001$ \\
\hline Overall confidence on the topic of FI & 4.19 & 7.00 & $<0.001$ \\
\hline
\end{tabular}

\section{Discussion}

Medical students lack awareness and knowledge of FI, and this study shows that the integration of a simple e-learning module can significantly improve this. To our knowledge, this is the first study that has evaluated an undergraduate teaching program for FI.

Our study showed little content in undergraduate teaching of FI by medical schools or governing organizations. Insufficient education of medical students may result in lower confidence in managing FI as a doctor and could also exert influences on their future career choices [10-12]. The introduction of standardized undergraduate criteria for FI knowledge by relevant professional bodies and medical schools could help ensure this debilitating condition is not overlooked.

The management of FI can be greatly improved through early detection and appropriate expertise [2]. In our study, over $80 \%$ had no teaching on FI at all during their undergraduate studies. Our study also demonstrates that medical students see patients with bowel dysfunction in a range of departments. Those who responded to the questionnaire aimed to specialize in a variety of areas all of which could involve treating patients with FI. Accessing the correct services for these patients can be challenging so an awareness from a range of specialties at all grades of training is crucial. Adequate education regarding FI is therefore important for medical students in preparation for the careers as doctors.

The use of focus groups is endorsed by AMEE [9] and enabled the students in our study to feedback on their experiences and expectations. The focus group identified that medical students generally preferred tutorials and bedside teaching as they enabled more interaction with tutors. The implementation of these methods for FI was identified by the group as being challenging due to the personal nature of the condition and lack of reliable access to patients. An interactive e-learning module was a pragmatic way to integrate FI teaching flexibly within the student timetable.

E-learning has been an effective innovation in medical education [13-15] with the accessibility of computers, phones and electronics facilitating this method. Their ease of use should avoid distracting from time required for other aspects of the curriculum. Resources can be accessed at the convenience of the learner and repeated during under or post graduate training. The development of e-learning modules can be done with programs which can then be updated with new evidence or guidance. Xerte is free, user friendly and enables clinicians to develop online educational resources.

Our methodology of developing an educational tool to address gaps in undergraduate knowledge could easily be transferable to other subject areas. The medical school at Cardiff University will be introducing the online tutorial created in this study to their undergraduate program. It can then be accessed when required to supplement learning during undergraduate training. It seems inevitable that with current advances, technology will have an increasing role in medical education.

Limitations of this study include the small numbers in the discussion groups and response rates for the questionnaires. Attempts to maximize this included the use of a variety of recruitment strategies but this still would not have captured every medical undergraduate at the University. Despite only nine students being involved, we found the discussion group to be extremely productive and allowed 
an excellent insight to the requirements of our undergraduates. Our experience has found that working in these smaller, informal groups allows more interaction to take place as the environment is less intimidating. The trial of the e-learning module with 20 students is again a small number. Despite this the pre and post questionnaires demonstrated statistical significance and therefore the utility of our intervention. In future, the effectiveness of this e-module should be re-evaluated with a larger cohort of students.

\section{Conclusions}

There are shortfalls in the undergraduate knowledge requirements regarding FI, especially considering its prevalence and serious consequences on quality of life. E-learning modules can help bridge this deficit in medical schools and could be applied to other areas.

Author Contributions: C.L.-Contributed to the literature searches, design of the study, data collection, publication of the e learning module, data analysis and write up of the manuscript. J.P.-Contributed to the literature searches, data analysis and write up of the manuscript. N.R.- Contributed to the design of the study, data collection and publication of the e learning module. J.C.-Contributed to the design of the study, data collection, publication of the e learning module, write up of the manuscript and was overall supervisor to the project. All authors have read and agreed to the published version of the manuscript.

Funding: This research received no external funding.

Conflicts of Interest: The authors declare that they have no competing interests.

$\begin{array}{ll}\text { Abbreviations } \\ \text { BGS } & \text { British Geriatric Society } \\ \text { FI } & \text { fecal incontinence } \\ \text { GMC } & \text { General Medical Council } \\ \text { RCOG } & \text { Royal College of Obstetricians and Gynaecologists } \\ \text { RCPCH } & \text { Royal College of Paediatricians and Child Health } \\ \text { RCS } & \text { Royal College of Surgeons }\end{array}$

\section{References}

1. Bharucha, A.E.; Dunivan, G.; Goode, P.S.; Lukacz, E.S.; Markland, A.D.; Matthews, C.A.; Mott, L.; Rogers, R.G.; Zinsmeister, A.R.; Whitehead, W.E.; et al. Epidemiology, pathophysiology, and classification of fecal incontinence: State of the science summary for the National Institute of Diabetes and Digestive and Kidney Diseases (NIDDK) workshop. Am. J. Gastroenterol. 2015, 110, 127-136. [CrossRef] [PubMed]

2. Hayden, D.M.; Weiss, E.G. Fecal incontinence: Etiology, evaluation, and treatment. Clin. Colon Rectal Surg. 2011, 24, 64-70. [CrossRef] [PubMed]

3. Saldana, R.N.; Kaiser, A.M. Fecal incontinence-Challenges and solutions. World J. Gastroenterol. 2017, 23, 11-24. [CrossRef] [PubMed]

4. Meyer, I.; Richter, H.E. Impact of fecal incontinence and its treatment on quality of life in women. Women's Health 2015, 11, 225-238. [CrossRef] [PubMed]

5. Johannessen, H.H.; Morkved, S.; Stordahl, A.; Sandvik, L.; Wibe, A. Anal incontinence and Quality of Life in late pregnancy: A cross-sectional study. BJOG Int. J. Obstet. Gynaecol. 2014, 121, 978-987. [CrossRef] [PubMed]

6. Whitehead, W.E.; Borrud, L.; Goode, P.S.; Meikle, S.; Mueller, E.R.; Tuteja, A.; Weidner, A.; Weinstein, M.; Ye, W. Fecal incontinence in US adults: Epidemiology and risk factors. Gastroenterology 2009, 137, 512-517, 517.e1-2. [CrossRef] [PubMed]

7. Deutekom, M.; Dobben, A.C.; Dijkgraaf, M.G.W.; Terra, M.P.; Stoker, J.; Bossuyt, P.M.M. Costs of outpatients with fecal incontinence. Scand. J. Gastroenterol. 2005, 40, 552-558. [CrossRef] [PubMed]

8. Thekkinkattil, D.K.; Lim, M.; Finan, P.J.; Sagar, P.M.; Burke, D. Awareness of investigations and treatment of faecal incontinence among the general practitioners: A postal questionnaire survey. Colorectal Dis. 2008, 10, 263-267. [CrossRef] [PubMed] 
9. Artino, A.R., Jr.; La Rochelle, J.S.; Dezee, K.J.; Gehlbach, H. Developing questionnaires for educational research: AMEE Guide No. 87. Med. Teach. 2014, 36, 463-474. [CrossRef] [PubMed]

10. Lee, M.J.; Drake, T.M.; Malik, T.A.; O'Connor, T.; Chebbout, R.; Daoub, A.; Wild, J.R.L. Has the bachelor of surgery left medical school?-A national undergraduate assessment. J. Surg. Educ. 2016, 73, 655-659. [CrossRef] [PubMed]

11. Ek, E.W.; Ek, E.T.; Mackay, S.D. Undergraduate experience of surgical teaching and its influence and its influence on career choice. ANZ J. Surg. 2005, 75, 713-718. [CrossRef] [PubMed]

12. Marshall, D.C.; Salciccioli, J.D.; Walton, S.-J.; Pitkin, J.; Shalhoub, J.; Malietzis, G. Medical Student Experience in Surgery Influences Their Career Choices: A Systematic Review of the Literature. J. Surg. Educ. 2015, 72, 438-445. [CrossRef] [PubMed]

13. Vaona, A.; Banzi, R.; Kwag, K.H.; Rigon, G.; Cereda, D.; Pecoraro, V.; Tramacere, I.; Moja, L. E-learning for health professionals. Cochrane Database Syst. Rev. 2018, 1, CD011736-CD. [CrossRef]

14. Masic, I. E-learning as new method of medical education. Acta Inform. Med. 2008, 16, 102-117. [CrossRef]

15. Choules, A.P. The use of elearning in medical education: A review of the current situation. Postgrad. Med. J. 2007, 83, 212-216. [CrossRef] [PubMed]

(C) 2020 by the authors. Licensee MDPI, Basel, Switzerland. This article is an open access article distributed under the terms and conditions of the Creative Commons Attribution (CC BY) license (http://creativecommons.org/licenses/by/4.0/). 